\title{
The Effects Of Extroversion On Conflict Resolution In Student Teams: A Cross-Cultural Comparison
}

\author{
Armen Tashchian, Kennesaw State University, USA \\ William R. Forrester, Kennesaw State University, USA \\ Maria Kalamas, Kennesaw State University, USA
}

\begin{abstract}
This paper reports the results of a cross-cultural investigation of the role of Extroversion in determining the conflict resolution styles of business students in the United States and the Republic of Armenia. PLS modeling showed that Extroversion was associated with the Dominating style among US students and with the Compromising and Obliging styles among Armenian students. Extroversion was associated with the Integrating style in both cultures. Findings are discussed along with their implications for cross-cultural research.
\end{abstract}

Keywords: Extroversion; Conflict-Resolution; Cross-Cultural Comparison

\section{INTRODUCTION}

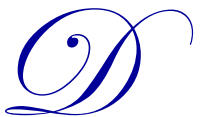

ifferent regions of the world, and countries within those regions, vary greatly in their approaches to resolving conflicts, and numerous studies have documented the existence of differences in resolution preferences among different nationality, cultural, and ethnic groups (Awang \& Roach-Duncan, 2010). Kozan (1997) proposed that different groups resolve conflicts using three fundamentally different approaches. Groups using a confrontational approach view conflicts as consisting of sub-issues which present opportunities for compromise. Those using a harmony approach view conflicts as existing in their totalities without sub-issues and reach resolution through observance of mutual obligations and status orderings. Those using a regulative approach define conflicts in terms of general principles and resolve conflicts using bureaucratic means, often with the involvement of third parties.

This three-approach typology has been useful in guiding research and has allowed investigators to document differences in resolution approaches in different settings. Studies have described ways in which preferences for these approaches differ among people of different national, ethnic, and cultural groups. Overall, these studies are consistent in showing cultural differences in deference to status power, use of regulation, and integration of interests. They have also shown that these differences lead to different conflict handling styles. For example, Tinsley (1998) found that Japanese, American, and German business managers differed significantly in their deference to status power, reliance on regulations, and ability to integrate interests of conflicting parties.

In a large scale study of Turkish business employees, Kozan and Ergin (1999) showed that resolution approaches varied depending upon the degree to which participants had been acculturated into Western values. Those having stronger traditional and conformity values were more likely to prefer avoidance or reliance upon third parties for resolution than those who were more westernized. Similarly, Awang and Roach-Duncan (2010) found that in comparison to US negotiators, Chinese and Asian negotiators showed a greater propensity for avoiding risk and avoiding conflict, and for deferring to negotiating parties with higher social status. Other studies have documented similar patterns when comparing Latin American, U.S., and Western European negotiators and when comparing conflict strategies used by British White, Indian, and African Black ethnic groups (Awang \& RoachDuncan, 2010; Makgosa \& Kang, 2009). 


\section{Conflict Resolution Styles and Extroversion}

Conflict is defined as a situation in which people are aware that their own wishes are incompatible with the wishes of others or when people become frustrated in their efforts to achieve important goals (Boulding, 1962). Theorists identify five conflict resolution styles based on the dimensions of concern for one's own position and concern for the position of the other party (Rahim \& Manger, 1995). The five styles are identified as integrating, obliging, dominating, avoiding, and compromising. Researchers have described characteristics and behaviors associated with each style (Booher, 1999; Munduate et al., 1999).

In the obliging style, people neglect their own needs in order to satisfy the needs of other parties. This yields lose-win outcomes and is considered a self-sacrifice style. Obliging is a good strategy for unimportant issues and for situations in which maintaining harmony is more valuable than a specific outcome. In the dominating style, individuals are generally firm in pursuing their side of an argument and use power to win in a conflict. The dominating style produces a win-lose outcome because one of the parties is aggressive and attempts to make sure that his or her needs are met regardless of the needs of the other party. Dominating is appropriate in emergency situations, but may require unpopular actions.

The avoiding style results in a lose-lose outcome because both parties refrain from communicating their needs, so neither has any needs met. The avoiding style is associated with withdrawal and sidestepping. The compromising style leads to a no-win/no-lose outcome. Both parties give up something to reach a mutually acceptable solution; however, this approach prevents both parties from meeting all their needs. Compromise is appropriate where the issue is important to all parties but not worth an extended fight. Individuals using an integrating style interact with others in a win-win manner. These people assertively speak up for their needs; they are open, exchange information and examine the differences between parties in order to reach a solution acceptable to both parties. The integrating style is the best approach in longer-term relationships and recurring situations, when outcomes are too important to compromise, and where buy-in is necessary for workable outcomes.

The use of personality dimensions to explain cross cultural differences in conflict style preferences continues to be very promising because of evidence that links personality with conflict styles, and other work linking personality to cultural differences. In 1998, Moberg proposed that personality traits could be used to predict conflict resolution preferences and presented evidence that facets of the Big-Five Personality dimensions were significantly associated with use of non-confrontational, confrontational, compromising, and controlling strategies (Moberg, 1998). In a 2011 study, Migliore was able to show that these personality traits were correlated with Hofstede's cultural dimensions of individualism, time orientation, masculinity, power distance, and uncertainty avoidance (Migliore, 2011; Hofstede, 1980).

To date, research into the moderating effects of personality on conflict resolution has produced mixed results. This may be due to differences in the validity of measures in different cultures, differences in the distributions of personality traits in different cultures, or different roles of the personality variables themselves (Konstabel, Realo, \& Kallasmaa, 2002). In this study, the choice was made to focus solely on the effects of extroversion. Extroversion is defined as a personality trait characterized by energy, cheerfulness, and sociability (Mooradian \& Swan, 2006). Past studies have shown that extroversion is significantly associated with each of the conflict resolution styles (Wood \& Bell, 2008; Moberg, 1998). Furthermore, extroversion is a construct that is robust across cultures (Mooradian \& Swan, 2006). In addition, extroversion is highly correlated with assertiveness and domineering; traits that are viewed differently in different cultures and that have been linked to negotiation outcomes (Ma \& Jaeger, 2010; Awang \& Roach-Duncan, 2010).

The purpose of this paper is to report the results of a study of the role of extroversion in determining conflict resolution choices. The study compared teams of business students in the United States with similar teams in the Republic of Armenia. 


\section{METHODOLOGY}

Data for this study were collected in the United States and Armenia respectively. In both cases the sample was collected in three phases and similar procedures were used to keep the data collection consistent and the data comparable.

\section{Study 1 - U.S. Sample}

Subjects for the U.S. sample were 127 graduate business students (46 percent male) from a southeastern university. The average age of respondents was 27.2 years. Data were collected in three phases. During the first phase, students were assigned to teams. Team memberships were voluntary. After team formation, students provided baseline personality information using the Neo-Five-Factor Inventory (Neo-FFI). This instrument measures respondents' personality on the dimensions of agreeableness, conscientiousness, extraversion, neuroticism and openness.

Phase 2 took place approximately six weeks later. Students provided information using the Work Group Characteristics Inventory (Campion, Medsker, \& Higgs, 1993). They also reported their perceptions of the social and task cohesiveness of their teams (Carless \& DePaola, 2000).

Phase 3 occurred at the end of the semester. Students indicated their perceptions of team effectiveness and the strategies they had used to resolve conflicts that had arisen in their teams. Students reported their conflict resolution preferences using the Rahim Organizational Conflict Inventory (ROCI-II) (Rahim \& Magner, 1995).

\section{Study 2 - Armenian Sample}

Data for the Armenian sample were collected in three phases, similar to the procedure described above. Study 2 was conducted with 114 graduate business students in Armenia (40 percent male). The students were enrolled in an English language MBA program and were proficient in English. The students had an average age of 26 years and a minimum of three years of full-time work experience.

The relationships between Extroversion and conflict resolution styles were tested using partial least squares structural equation modeling (PLS-SEM). PLS-SEM is similar to multiple regression analysis with the objective of maximizing the explained variance of endogenous latent constructs (dependent variables). PLS-SEM is well suited for exploratory research with the aim of theory development.

\section{RESULTS}

Table 1 presents the average scale mean and Cronbach's alpha for Extroversion and each conflict resolution style for the U.S. and Armenian samples. Cronbach's alphas indicate that internal validity levels were acceptable for all measures of both samples.

Table 1: Scale Properties for Measures Used in the Study

\begin{tabular}{|c|c|c|c|c|c|}
\hline & \multirow[b]{2}{*}{$\begin{array}{l}\text { Number of } \\
\text { Items }\end{array}$} & \multicolumn{2}{|c|}{ U.S. Sample } & \multicolumn{2}{|c|}{ Armenian Sample } \\
\hline & & Item Mean & $\begin{array}{c}\text { Cronbach's } \\
\text { Alpha }\end{array}$ & Item Mean & $\begin{array}{c}\text { Cronbach's } \\
\text { Alpha }\end{array}$ \\
\hline \multicolumn{6}{|l|}{ Conflict Resolution Styles } \\
\hline Avoiding (AVD) & 6 & 3.01 & 0.825 & 2.96 & 0.712 \\
\hline Compromising (COM) & 4 & 3.92 & 0.705 & 3.23 & 0.654 \\
\hline Dominating (DOM) & 5 & 3.97 & 0.854 & 2.95 & 0.868 \\
\hline Integrating (INT) & 7 & 4.38 & 0.863 & 1.77 & 0.817 \\
\hline Obliging (OBL) & 6 & 3.68 & 0.687 & 2.51 & 0.754 \\
\hline \multicolumn{6}{|l|}{ Personality Measure } \\
\hline Extroversion (EXT) & 12 & 3.81 & 0.778 & 2.41 & 0.745 \\
\hline
\end{tabular}


Figure 1 shows the impact of Extroversion on the five conflict resolution styles. The model hypothesizes that Extroversion has a direct impact on preference for each style. Testing the full model for both samples reveals that only certain paths of the full model are significant. Figure 2 displays the significant paths along with the path coefficients.

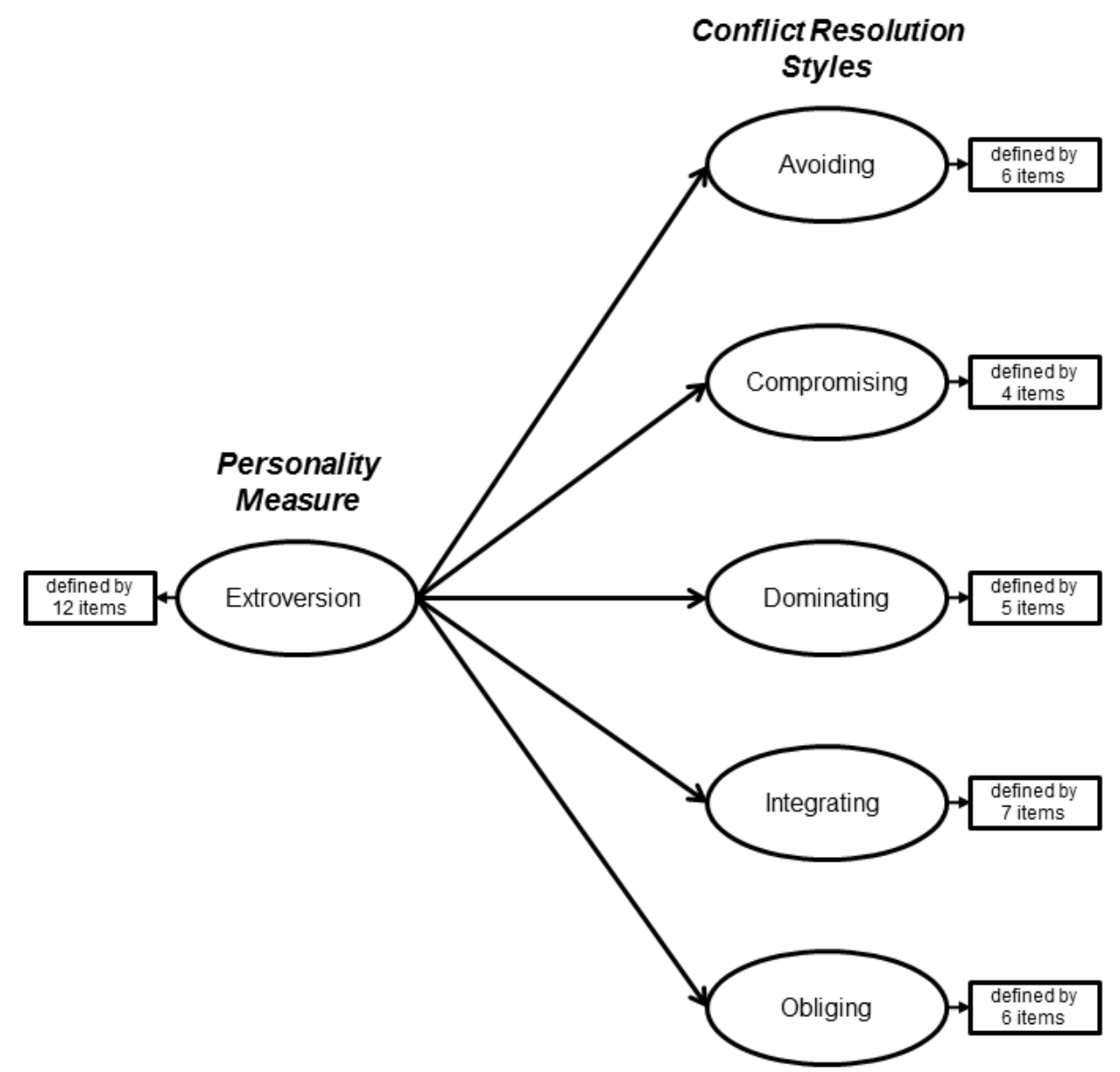

Figure 1: Hypothesized Relationships between Extraversion and Conflict Resolution Styles

Figure 2 shows that for the U.S. sample, Extroversion was related to respondents' preferences for the Integrating (EXT $\rightarrow \mathrm{INT}=0.232, \mathrm{t}=2.17)$ and Dominating $(\mathrm{EXT} \rightarrow \mathrm{DOM}=0.253, \mathrm{t}=2.14)$ styles. Individuals high in extroversion enjoy talking to people and are active, energetic, cheerful and high spirited. These individuals are willing to bring all concerns out in the open and collaborate with team members to find win-win (integrating) solutions. They are also willing to use their influence, authority, and expertise to get their ideas accepted and use their power to win and to have decisions in their favor (dominating strategy).

For the Armenian sample, Extroversion was related to respondents' preferences for the Integrating, Compromising and Obliging styles. It appears that Armenian students were more likely to use non-confrontational strategies when dealing with conflict. Specifically, they were willing to exchange information, collaborate and integrate their ideas with other team members to find a win-win solution $($ EXT $\rightarrow$ INT $=0.469, t=5.39$ ). They were also willing to find a middle ground for breaking deadlines and resolving impasse $(\mathrm{EXT} \rightarrow \mathrm{COM}=0,455, \mathrm{t}=$ 6.48). Finally, the Armenian students were willing to neglect their own needs in order to satisfy the needs of the other party. They allowed concessions and went along with wishes of other team members. This approach yields a lose-win outcome and is considered a self-sacrifice style $(\mathrm{EXT} \rightarrow \mathrm{OBL}=0.340, \mathrm{t}=2.91)$. 


\section{US SAMPLE}

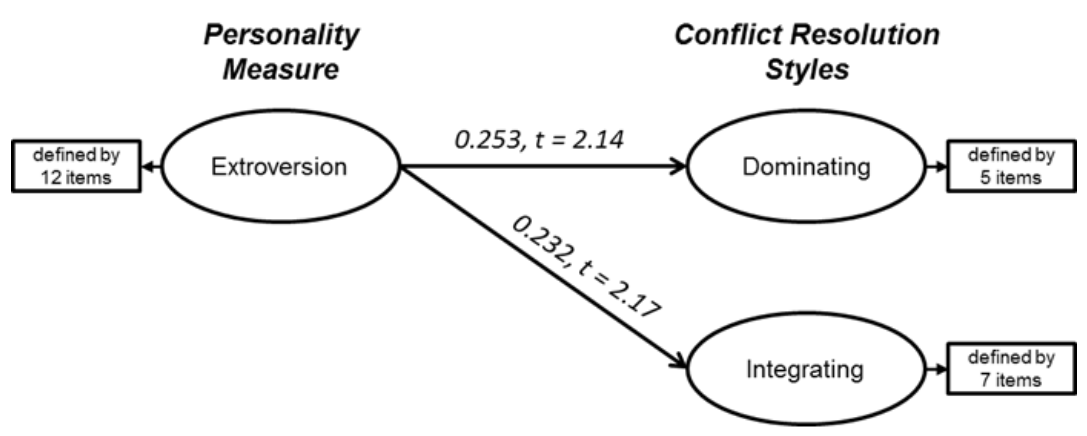

ARMENIAN SAMPLE

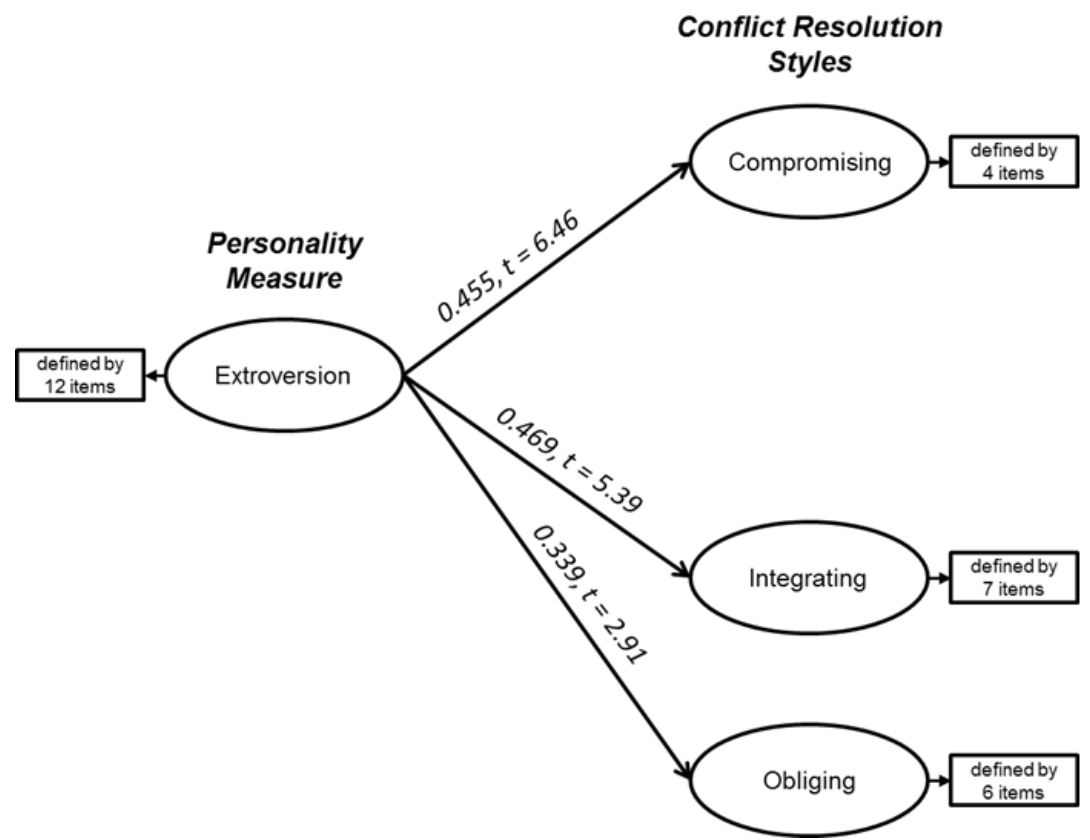

Figure 2: Extraversion Influencing Conflict Resolution Styles in Student Teams

\section{CONCLUSIONS}

Individuals of different cultural backgrounds possess different values and norms that reflect their cultural heritage. These differences manifest themselves in a variety of ways, but most prominently between individualism and collectivism, which accounts for the greatest variance in group work priorities (Triandis, 1989). Collectivist cultures place greater emphasis on the needs and goals of the group, social norms and shared beliefs. They are also more likely than individualists to sacrifice personal interests for the attainment of group goals and enjoy doing what the group expects of them (Bontempo, Lobel, \& Triandis, 1980). The collectivists emphasize the value of cooperation, whereas individualists emphasize domination and competition. For example, Leung (1988) found that collectivists prefer cooperative approaches, like bargaining and mediation, to conflict resolution, whereas individualists tend to perform jobs that include independent tasks and the rewards of team work has less appeals for them because such rewards must be shared rather than personally consumed. 
Cross-cultural studies have shown that North Americans tend to be individualists and that people of NearEast and Middle-East tend to be collectivists (Hofstede, 1980; Inkeles, 1983). Our study confirms that U.S. students exhibited higher preferences for dominating and integrating styles, while the Armenian students showed more cooperative tendencies like bargaining and mediation. As such, this study adds to the growing body of evidence that cultural context moderates relationships between personality variables with conflict resolution strategies. Results clearly indicate a significant preference for compromising and obliging strategies among Armenian students, but no similar preference among the U.S. students. This is consistent with results of previous studies which show U.S. culture to be more individualistic than Armenian culture and provides additional evidence that lower individualism correlates with lower propensity toward compromising and obliging solutions (Westerman et al., 2009; Kozan, 1997; d'Astous \& Boujbel, 2007).

To enhance the clarity of results, future studies should incorporate broader measures of personality. Although it is widely accepted that the Neo-FFI is robust and reliable across cultures, some researchers have noted problems arising from the translation of the Neo FFI from English into other languages. Some have even argued that a two-dimensional representation of personality is more applicable across cultures than the five-dimensional approach used here (Schmit, Kihm, \& Robie, 2000). It should also be noted that cultural dimensions were not measured in this study and, as such, future studies should include measures for the individualism vs. collectivism dimension of culture, as well as the remaining dimensions which were identified by Hofstede. Finally, there is growing evidence to suggest that additional information about the motives of the parties in the conflict are useful in predicting conflict strategies, regardless of cultural context (Fu et al., 2007), which is important to consider in follow-up studies.

\section{AUTHOR INFORMATION}

William Forrester received his Ph.D. in Marketing in 1986 from the University of Tennessee. He currently works as Professor of Marketing in the Coles College of Business at Kennesaw State University. He has published in the Journal of the Academy of Marketing Science, the Journal of Economic Psychology, and the Journal of Applied Business Research, and numerous other outlets. E-mail: wforrest@kennesaw.edu (Corresponding author)

Armen Tashchian is Professor of Marketing in the Coles College of Business at Kennesaw State University. He received his Ph.D. in Marketing from the University of Texas in 1980. He has published in numerous academic journals including the Journal of Marketing, the Journal of Marketing Research, and the Journal of the Academy of Marketing Science. E-mail: atashchi@kennesaw.edu

Maria Kalamas is an Associate Professor, Department of Marketing and Professional Sales, Coles College of Business, Kennesaw State University. She has published her research in leading journals including the Journal of Business Research, International Marketing Review, Psychology \& Marketing, Journal of Strategic Marketing, and Journal of Consumer Marketing. Maria has also presented her work at several national and international academic conferences. Email: mkalamas@kennesaw.edu

\section{REFERENCES}

1. Awang, F., \& Roch-Duncan, J. (2010). Cultural differences and their effects on conflict resolution in business settings. Journal of Global Business Education, 10(1), 27-36.

2. Booher, D. (1999). Resolving conflict. Executive Excellence, 16(5), 5.

3. Boulding, K. (1962). Conflict and defense. New York, NY: Harper and Row.

4. Bontempo, R., Lobel, S. A., \& Triandis, H. C. (1990). Compliance and value internalization in Brazil and the U.S.: Effects of allocentrism and anonymity. Journal of Cross-Cultural Psychology, 21, 200-213.

5. Campion, M. A., Medsker, G. J., \& Higgs, A. (1993). Relations between work group characteristics and effectiveness: implications for designing effective work groups. Personnel Psychology, (4), 823.

6. Carless, S. A., \& DePaol, C. (2000). The measurement of cohesion in work teams. Small Group Research, 31(1), 71-88.

7. d'Astous, A., \& Boujbel, L. (2007). Positioning countries on personality dimensions: Scale development and implications for country marketing. Journal of Business Research, 60(3), 231. 
8. Fu, J. H.-Y., Morris, M. W., Sau-lai, L., Chao, M., \& et al. (2007). Epistemic motives and cultural conformity: Need for closure, culture, and context as determinants of conflict judgments. Journal of Personality and Social Psychology, 92(2), 191-207.

9. Hofstede, G. (1980). Culture's consequences: International differences in work-related values. Beverly Hills, CA: Sage.

10. Inkeles, A. (1983). The American character. The Center Magazine, 16, 25-3.

11. Konstabel, K., Realo, A., \& Kallasmaa, T. (2002). Exploring the sources of variations in the structure of personality traits across cultures. In R. R. McCrae \& J. Allik (Eds.). The five-factor model of personality across cultures (pp. 29-52). New York: Kluwer Academic/Plenum Publishers.

12. Kozan, M. K. (1997). Culture and conflict management: A theoretical framework. International Journal of Conflict Management, 8(4), 338-360.

13. Kozan, M. K., \& Ergin, C. (1999). The influence of intra-cultural value differences on conflict management practices. International Journal of Conflict Management, 10(3), 249-267.

14. Leung, K. (1988). Some determinants of conflict avoidance. Journal of Cross-Cultural Psychology, 19, $125-136$.

15. Ma, Z., \& Jaeger, A. M. (2010). A comparative study of the influence of assertiveness on negotiation outcomes in Canada and China. Cross Cultural Management, 17(4), 333-346.

16. Makgosa, R., \& Kang, J. (2009). Conflict resolution strategies in joint purchase decisions for major household consumer durables: A cross-cultural investigation. International Journal of Consumer Studies, 33(3), 338-348.

17. Migliore, L. A. (2011). Relation between big five personality traits and Hofstede's cultural dimensions. Cross Cultural Management, 18(1), 38-54.

18. Moberg, P. J. (1998). Predicting conflict strategy with personality traits: Incremental validity and the five factor model. International Journal of Conflict Management, 9(3), 258-285.

19. Mooradian, T. A., \& Swan, K. S. (2006). Personality-and-culture: The case of national extraversion and word-of-mouth. Journal of Business Research, 59(6), 778-785.

20. Munduate, L., Ganaza, J., Peiro, J. M., \& Euwema, M. (1999). Patterns of styles in conflict management and effectiveness. International Journal of Conflict Management, 10(1), 5-24.

21. Rahim, M. A., \& Nace R. Magner. (1995). Confirmatory factor analysis of the styles of handling interpersonal conflict: First-order factor model and its invariance across groups. Journal of Applied Psychology, 80(1), 122.

22. Schmit, M. J., Kihm, J. A., \& Robie, C. (2000). Development of a global measure of personality. Personnel Psychology, 53(1), 153-193.

23. Tinsley, C. (1998). Models of conflict resolution in Japanese, German, and American cultures. Journal of Applied Psychology, 83(2), 316-323.

24. Triandis, H. C. (1989). Cross-cultural studies of individualism-collectivism. In J. J. Berman (Ed.), Nebraska Symposium on motivation: Cross-cultural perspectives, 37, 41-133. Lincoln: University of Nebraska Press.

25. Westerman, J. W., Beekun, R. I., Daly, J., \& Vanka, S. (2009). Personality and national culture. Management Research News, 32(8), 767-781.

26. Wood, V. F., \& Bell, P. A. (2008). Predicting interpersonal conflict resolution styles from personality characteristics. Personality and Individual Differences, 45, 126-131. 


\section{NOTES}

